\title{
SOME COMPLETELY MONOTONIC FUNCTIONS INVOLVING THE $q$-GAMMA FUNCTION
}

\author{
PENG GAO
}

Abstract. We present some completely monotonic functions involving the $q$-gamma function that are inspired by their analogues involving the gamma function.

Mathematics subject classification (2010): 33D05.

Keywords and phrases: Completely monotonic function, $q$-gamma function.

\section{REFERENCES}

[1] H. Alzer, Some gamma function inequalities, Math. Comp., 60 (1993), 337-346.

[2] H. Alzer, On some inequalities for the gamma and psi functions, Math. Comp., 66 (1997), 373-389.

[3] H. AlZER, Sharp bounds for the ratio of q-gamma functions, Math. Nachr., 222 (2001), 5-14.

[4] H. AlzER, Sharp inequalities for the digamma and polygamma functions, Forum Math., 16 (2004), 181-221.

[5] H. Alzer And N. BATIR, Monotonicity properties of the gamma function, Appl. Math. Lett., 20 (2007), 778-781.

[6] H. Alzer And C. Berg, Some classes of completely monotonic functions, II., Ramanujan J., 11 (2006), 225-248.

[7] J. Bustoz And M. E. H. Ismail, On gamma function inequalities, Math. Comp., 47 (1986), 659667.

[8] N. Elezović, C. GIORdANO AND J. PeČARIĆ, A geometric mean inequality and some monotonicity results for the q-gamma function, Math. Inequal. Appl., 1 (1998), 253-258.

[9] N. Elezović, C. Giordano And J. PeČArić, The best bounds in Gautschi's inequality, Math. Inequal. Appl., 3 (2000), 239-252.

[10] N. Elezović And J. PeČARIĆ, Differential and integral $f$-means and applications to digamma function, Math. Inequal. Appl., 3 (2000), 189-196.

[11] P. GAO, A note on the volume of sections of $B_{p}^{n}$, J. Math. Anal. Appl., 326 (2007), 632-640.

[12] P. GAO, Some monotonicity properties of gamma and q-gamma functions, ISRN Math. Anal., (2011) 2011, Art. ID 375715, 15 pp.

[13] A. Z. GRINSHPAN AND M. E. H. ISMAIL, Completely monotonic functions involving the gamma and q-gamma functions, Proc. Amer. Math. Soc., 134 (2006), 1153-1160.

[14] M. E. H. ISMAIL AND M. E. MULDOON, Inequalities and monotonicity properties for gamma and $q$ gamma functions, In: Approximation and computation, Internat. Ser. Numer. Math., 119, Birkhäuser, Boston, 1994, 309-323.

[15] H.-H. KAIRIES AND M. E. Muldoon, Some characterizations of $q$-factorial functions, Aequationes Math., 25 (1982), 67-76.

[16] D. Kershaw, Some extensions of W. Gautschi's inequalities for the gamma function, Math. Comp., 41 (1983), 607-611.

[17] T. H. KoORNWINDER, Jacobi functions as limit cases of q-ultraspherical polynomials, J. Math. Anal. Appl., 148 (1990), 44-54.

[18] C. Krattenthaler And H. M. SRIVAStava, Summations for basic hypergeometric series involving a q-analogue of the digamma function, Comput. Math. Appl., 32 (1996), 73-91. 
[19] M. E. Muldoon, Some monotonicity properties and characterizations of the gamma function, Aequationes Math., 18 (1978), 54-63. A. B. Olde DAAlHuis, Asymptotic expansions for q-gamma, $q$-exponential, and q-Bessel functions, J. Math. Anal. Appl., 186 (1994)

[20] S.-L. QIU AND M. VuORINEN, Some properties of the gamma and psi functions, with applications, Math. Comp., 74 (2005), 723-742.

[21] K. B. Stolarsky, Generalizations of the logarithmic mean, Math. Mag., 48 (1975), 87-92. 